\title{
ENSINO DE DIDÁTICA: UM ESTUDO SOBRE CONCEPC̣ÕES E PRÁTICAS DE PROFESSORES FORMADORES
}

Giseli Barreto da Cruz

Marli Eliza Dalmazo Afonso de André"*

RESUMO: O texto analisa concepções e práticas de professores de Didática de três universidades, tendo por base a perspectiva de Didática fundamental proposta por Candau (1983) e sua incorporação pelos programas de formação de professores. Foram realizados quatro grupos de discussão, 40 entrevistas e 90 horas de observação de aulas. Buscou-se conhecer quem é esse professor que ensina Didática, captar suas visões sobre Didática e identificar suas práticas em sala de aula para compreender como as concepções e práticas defendidas fundamentam o aprendizado da docência. O quadro teórico da pesquisa foi elaborado com base em Roldão (2007), Gauthier (2006), Cochran-Smith \& Lytle (1999), André et al. (2010) e Zeichner (2009). Os resultados revelaram a tendência de ensinar Didática a partir do tratamento de temas necessários à formação de professores, sem, no entanto, se manifestar a preocupação com a afirmação da Didática fundamental, caracterizada pela multidimensionalidade do processo de ensinar e aprender.

Palavras-chave: Didática. Currículo e formação de professores. Ensino de Didática. Professor formador.

\footnotetext{
* Doutora em Educação pela Pontifícia Universidade Católica do Rio de Janeiro (PUC-RIO); Professora Adjunta da Faculdade de Educação da Universidade Federal do Rio de Janeiro (UFRJ) e Coordenadora do Grupo de Estudos e Pesquisas em Didática e Formação de Professores (GEPED). Email: giselicruz@ufrj.br ** Doutora em Psicologia da Educação pela University of Illinois; Professora Titular aposentada na Faculdade de Educação da Universidade de São Paulo (USP) e Professora do Programa de Estudos Pósgraduados em Educação: Psicologia da Educação da Pontifícia Universidade Católica de São Paulo (PUC. SP). Email: marliandre@pucsp.br
} 


\section{TEACHING DIDACTICS: A STUDY ABOUT CONCEPTIONS AND PRACTICES OF INSTRUCTIONAL TEACHERS}

ABSTRACT: The present text analyses the concepts and practices of teaching Didactics in three universities based on the fundamental concept of Didactics proposed by Candau (1983) and to understand how it is assimilated by teachers into majoring programs. Researching procedures included 4 focus groups, 40 interviews with teachers and 90 hours of classroom observation. The objective was to know who is that teacher who teaches undergraduating courses in Didactics to capture his or her views on Didactics and to identify their classroom practices, in order to understand how their claims, concepts and practices find their will to teach. The theoretical framework of researching was elaborated in accordance to ideas defended by Roldão (2007), Gauthier (2006), Cochran-Smith \&Lytle (1999), André et al. (2010) and Zeichner (2009).The results demonstrated that there is a tendency to teach Didactics from the point of view of themes based on topics for teaching but with no concern to reinforce the fundamental Didactics. However, it is necessary to be aware of the suggestion found on Fundamentals Didactics which comes characterized by its multidimensionality in the process of teaching and learning.

Keywords: Didactics. Curriculum and Teaching Education. Teaching of Didactics. Teaching Educator.

\section{INTRODUCุ̃̃O}

Nosso interesse em conhecer o professor formador que ministra disciplinas relacionadas à Didática nos cursos de licenciatura teve algumas influências, entre as quais uma síntese integrativa das pesquisas realizada por André (2008) sobre a produção específica de Didática, com base nos 62 trabalhos apresentados no GT Didática da ANPEd - Associação Nacional de Pós-Graduação e Pesquisa em Educação, no período de 2003 a 2007. Para desenvolver essa síntese integrativa, André recorreu a proposições de Candau (2000) e Oliveira (2000), que realizaram um balanço de 20 anos de produção acadêmica da área no X Encontro de Didática e Prática de Ensino (Endipe). André considerou ainda os escritos de Oliveira (1997) e Pimenta (2000), que se debruçaram sobre as pesquisas da área nos anos de 1980 e 1990, e expressou sua estranheza face ao ocultamento do ensino da Didática como objeto de estudo no campo da Didática. No seu dizer,

Será que não precisamos saber o lugar que a disciplina Didática ocupa no currículo de formação de professores? Será que não queremos saber o que se 
ensina e como se ensina Didática hoje? Por que então esse ocultamento da agenda de pesquisas? Será que estamos nos precavendo de algo que não queremos ver? Essas são questões que exigem um esforço conjunto de reflexão e de tentativa de resposta e quiçá possam nos auxiliar a compreender como o campo da Didática vem se constituindo. (ANDRÉ, 2008, p. 499)

Uma breve retomada histórica da Didática nos ajuda a entender as circunstâncias que cercam esse ocultamento a que se refere André (2008). Tomando por base alguns estudos (CANDAU, 1983, 1988; MARTINS, 2008; OLIVEIRA, 1998, 1992; PIMENTA, 1997; VEIGA, 1989), pode-se afirmar que a Didática passou a ser fortemente contestada a partir dos anos de 1970, com a crítica às perspectivas escolanovista e tecnicista, denunciando a pseudoneutralidade do técnico e enfatizando a necessidade de se pensar a prática pedagógica como prática social. O campo da Didática que, até então, se forjava pela via de uma produção de natureza eminentemente técnica e prescritiva, experimentou uma fase de críticas contundentes, apontando, inclusive para a sua negação. Com a emergência de um novo pensamento pedagógico, a Didática instrumental é posta em questão.

Nesse sentido, os anos de 1980 foram referenciais na constituição do campo da Didática, assim como no contexto mais abrangente do campo educacional brasileiro. A década de 1980 foi caracterizada por significativa ampliação da produção acadêmica, essencialmente marcada pelas pedagogias contra-hegemônicas, voltadas para a educação e as possibilidades emancipatórias de transformação da sociedade. Dessa forma, a produção da Didática nos anos de 1980 experimentou uma grande renovação, resultante das mudanças que perpassaram o campo educacional e social nesse período. Uma série de encontros decorrentes do movimento dos educadores propiciou sua problematização, tecendo progressivamente mudanças paradigmáticas na área.

Um dos marcos dessa fase diz respeito ao desafio proposto por Candau (1983), até hoje recolocado, de superação de uma Didática exclusivamente instrumental pela construção de uma Didática fundamental, essencialmente articulada à problemática da educação na sociedade. A proposta da Didática fundamental defendida por Candau (1983) representou um amplo movimento de reação à Didática marcada pela neutralidade.

É importante destacar que, na defesa da Didática fundamental, a autora não negou a dimensão técnica, porém a ressituou do ponto de vista político. No seu entender, a prática pedagógica, objeto da 
Didática, por ser política, exige a competência técnica. Nessa direção, partiu para a defesa da interligação entre as dimensões humana, técnica, política e social, que dão relevo à multidimensionalidade do processo de ensinar e aprender, objeto da Didática. Essa perspectiva conscientemente trabalhada faria emergir o que chamou de Didática fundamental. Tal proposta teve ampla repercussão nos debates acadêmicos e na produção da área.

Entretanto, nos cursos de formação de professores, o ensino da Didática parece querer superar a tendência instrumental, mas sem conseguir definir o foco do que seria o fundamental. Para Libâneo (2008), a Didática corre o risco de ver enfraquecido o seu objeto, visto a dispersão que tem tomado conta de seu campo nos últimos anos. Segundo esse autor, o objeto da Didática diz respeito à mediação da aprendizagem feita pelo professor, aspecto que não tem recebido o tratamento devido nos cursos de formação docente. Questiona Libâneo (2008, p. 237): "Por que hoje os programas de didática tratam de todos os temas, menos daqueles que ajudam os professores a atuarem eficazmente nos processos de aprendizagem dos alunos?".

Pesquisa recente realizada por Libâneo (2011), sobre o panorama do ensino de Didática, das metodologias específicas e das disciplinas conexas nos cursos de Pedagogia, revela que, no Estado de Goiás, a análise das ementas dessas disciplinas "mostra que ao menos $70 \%$ delas expressam uma didática instrumental (...)" (LIBÂNEO, 2011, p. 29). No entanto, considerando nossas experiências em encontros de planejamento e de avaliação do ensino de Didática e no contato com colegas, percebemos que parece predominar uma abordagem de Didática que tende a ignorar o ensino de conteúdos ligados ao foco instrumental e priorizar diversos assuntos que envolvem a formação docente, sem que, necessariamente, o ensino e a aprendizagem sejam afirmados como o núcleo central da discussão. A essa percepção tácita se liga o que indicam estudos sobre formação de professores, tal como o de Gatti (2010), que aponta que a formação de professores, em especial a formação específica para o processo de ensinar, objeto da Didática, tem se dado de forma descontextualizada da escola, sem trabalhar com os licenciandos, futuros professores, o que e como ensinar. As conclusões da investigação sinalizam que o porquê de ensinar de alguma maneira é cotejado pelas ementas das disciplinas, notadamente marcadas pelo caráter disperso e plural, porém o que e como ensinar é apenas tangenciado no ementário.

No contexto da problemática encontra-se a discussão em torno da dispersão ou diversificação da Didática. Na visão de Candau 
(2009, p. 38), "mais do que uma questão de dispersão é possível interpretar esta realidade como um momento de desestabilização e diversificação, em que emerge uma pluralidade de enfoques, temáticas e problemáticas". No nosso entender, o ensino de Didática nos cursos de licenciatura se beneficia da diversificação, porém enfrenta o desafio de não perder o foco em face à pluralidade de temáticas e abordagens confluentes à área. Nossas observações apontam que a proposta de uma Didática que ajude o professor a entender o processo de ensino e aprendizagem para delineá-lo a partir de um contexto situado não tem sido assumida pelos cursos de formação inicial, ainda que o caráter prescritivo, próprio da Didática instrumental, pareça superado. Se o prescritivo não prevalece, mas o fundamental da Didática também não se estabelece, o que conta como Didática nos cursos de formação de professores?

Esse contexto nos desafiou a realizar uma pesquisa sobre concepções e práticas didáticas de professores formadores, com a intenção de investigar o que prevalece no ensino de Didática hoje, tendo por base a concepção de Didática fundamental proposta por Candau (1983) e sua assimilação nos programas de formação de professores. Neste artigo discutiremos os resultados obtidos com essa pesquisa, realizada no período de 2009 a 2012. A pesquisa foi pautada pelos seguintes objetivos: analisar concepções e práticas didáticas de professores formadores que atuam com Didática nos cursos de licenciatura de três universidades do Estado do Rio de Janeiro e compreender como as concepções e práticas defendidas fundamentam o aprendizado da docência. Nas partes subsequentes deste artigo, nos ocuparemos com explicações metodológicas, discussões teóricas que fundamentaram o nosso estudo e análise dos resultados, focalizando o perfil dos professores formadores investigados, as concepções de Didática por eles defendidas e as práticas didáticas depreendidas de suas aulas.

\section{METODOLOGIA}

O objeto do estudo e os objetivos estabelecidos apontaram para uma definição intencional e proposital dos sujeitos participantes, no sentido de assegurar a composição de um grupo essencialmente constituído de professores que ensinam Didática em cursos presenciais de licenciatura oferecidos por instituições universitárias. O procedimento de partida do estudo consistiu em escolher as instituições formadoras e localizar os docentes, cujas trajetórias de atuação correspondessem aos sujeitos almejados. 
No que diz respeito à escolha das instituições, consideramos o banco de dados do Ministério da Educação como fonte de consulta e procedemos ao levantamento de todas as universidades localizadas no Estado do Rio de Janeiro que oferecem cursos presenciais de licenciatura. A partir do mapeamento obtido, selecionamos três instituições - uma pública federal, uma pública estadual e uma privada - com base nos critérios de quantidade de cursos de licenciatura oferecidos e tempo de experiência no campo de formação de professores, na tentativa de investigar universidades experientes na formação docente que trabalham com vários cursos de licenciatura há muitos anos.

A abordagem metodológica consistiu na coleta de depoimentos obtidos através de entrevistas semiestruturadas, conjugadas com grupos de discussão compostos de até dez professores de cada universidade, além de observações de aulas. A entrevista favoreceu a captação das concepções do formador, e os grupos de discussão e as observações de aulas favoreceram a apreensão da razão pedagógica que sustenta o que faz o formador para ensinar Didática. É importante situar que o grupo de discussão tem representado um canal valioso de diálogo problematizador da prática profissional. Esse contexto exigiu, na condição de mediadores do grupo, a habilidade de intervir o mínimo possível, porém estimulando a reflexão sobre experiências definidoras das práticas didáticas dos participantes, tentando explorar as opiniões coletivas, e não apenas as individuais, tal como defende Mangold (1960 citado por WELLER, 2010).

O trabalho de campo registra a realização de dezoito entrevistas, dois grupos de discussão e dez aulas observadas na universidade pública federal; nove entrevistas, um grupo de discussão e dez aulas observadas na universidade pública estadual; treze entrevistas, um grupo de discussão, e dez aulas observadas na universidade privada, tal como indica o quadro abaixo:

\begin{tabular}{|c|c|c|c|c|}
\hline $\begin{array}{c}\text { COLETA DE } \\
\text { DADOS }\end{array}$ & $\begin{array}{c}\text { UNIVERSIDADE } \\
\text { PÚBLICA } \\
\text { FEDERAL }\end{array}$ & $\begin{array}{c}\text { UNIVERSIDADE } \\
\text { PÚBLICA } \\
\text { ESTADUAL }\end{array}$ & $\begin{array}{c}\text { UNIVERSIDADE } \\
\text { PRIVADA }\end{array}$ & TOTAL \\
\hline Entrevistas & 18 & 09 & 13 & 40 \\
\hline $\begin{array}{c}\text { Grupos de } \\
\text { Discussão }\end{array}$ & 02 & 01 & 01 & 04 \\
\hline $\begin{array}{c}\text { Observação de } \\
\text { aulas de um } \\
\text { dos professores } \\
\text { entrevistados }\end{array}$ & 10 & 10 & 10 & 30 \\
\hline
\end{tabular}

Tabela 1: Coleta de dados. 


\section{PERSPECTIVAS TEÓRICAS}

Procuramos operar teoricamente com conceitos, concepções, ideias e posições de autores que nos ajudassem a entender o processo de ensino e o aprendizado da docência. Dessa forma, o quadro teórico da pesquisa foi elaborado com base em Roldão (2007), Gauthier (1998), Cochran-Smith \& Lytle (1999), André et al. (2010) e Zeichner (2009).

Roldão (2007) argumenta que a ação de ensinar é o que caracteriza o docente ao longo do tempo, apesar de essa distinção decorrer de construção histórica e social em permanente evolução. $\mathrm{O}$ ato de ensinar pode ser compreendido pela perspectiva de "professar um saber", prevalecendo a postura do professor transmissor, com ênfase nos saberes de cunho disciplinar; como também pode ser compreendido na perspectiva de "fazer aprender alguma coisa a alguém", cuja postura é considerada mais pedagógica e envolve a pluralidade de saberes que um docente deve ter. A autora defende a hipótese de que a função de ensinar nas sociedades atuais deve ser marcada por uma dupla transitividade e pela mediação. Assim, ensinar deve ser assumido como o processo de fazer aprender alguma coisa a alguém, só se completando naquele que aprende, o que requer uma dupla transitividade (sujeitos que ensinam e aprendem) e a mediação (sujeitos que aprendem sob a mediação de quem ensina). Nesse sentido, buscamos problematizar como o ensino é compreendido e trabalhado pelos formadores de professores, tentando identificar o que prevalece: transmissão ou mediação?

Gauthier (1998), bastante envolvido com o movimento geral da pesquisa sobre o ensino, se propôs a investigar sua natureza, seus componentes, seu funcionamento, seus efeitos, enfim, trabalhar a favor do que chama de repertório de conhecimentos próprios ao processo de ensinar, descrevendo seis saberes essenciais: saberes disciplinares; saberes curriculares; saberes das ciências da educação; saberes da tradição pedagógica; saberes experienciais; saberes da ação pedagógica. Tardif (2002) e Shulman (2005) também se ocupam com os saberes e conhecimentos profissionais docentes, oferecendo importantes contribuições. Todavia, preferimos trabalhar com as ideias de Gauthier em face da problematização que faz sobre os saberes pedagógicos. Nosso estudo partiu do pressuposto de que a prática do formador deve ser parâmetro de constituição da própria prática profissional do futuro professor. Segundo Gauthier (1998), os saberes da ação pedagógica são pouco desenvolvidos no reservatório de saberes do professor. 
Tendo em vista que esses saberes fundamentam a sua prática de ensino, é fundamental que eles sejam postos em evidência por meio da própria atividade dos formadores para que os futuros professores reconheçam sua pertinência e especificidade.

As autoras norte-americanas Cochran-Smith \& Lytle (1999) se constituíram como peça-chave para fundamentação de nossa investigação porque distinguem três concepções de aprendizado de professores. O conhecimento-para-a-prática sustentada pela premissa de que saber mais conteúdo, mais teorias de educação, mais pedagogia, mais estratégias de ensino garante uma prática bem-sucedida. O conhecimento-na-prática, que está relacionado ao conhecimento em ação. Os bons professores são aqueles que apresentam e constroem problemas a partir das situações práticas, em toda a sua complexidade e diversidade, recorrendo a situações anteriores, bem como a uma variedade de outras informações. O como ensinar é marcado pela reflexão sobre a ação na sala de aula e a criação de conhecimento em ação para dar conta de novas situações de aprendizagem. E o conhecimento-da-prática, que parte do pressuposto de que o conhecimento que os professores devem ter para ensinar bem decorre de investigação sistemática do ensino, dos alunos e do aprendizado, bem como do conteúdo, do currículo e da escola. Para que isso aconteça, os professores devem aprender colaborativamente, em comunidades de investigação e/ou redes, buscando, com os outros, construir um conhecimento significativo local, em que a investigação é reconhecida como parte de um esforço maior de transformar o ensino, o aprendizado e a escola.

A contribuição dessas pesquisadoras vem ao encontro de nosso interesse pela Didática e o aprendizado da docência. Procuramos saber o que os formadores pensam e o que realizam em suas aulas de Didática, espaço de problematização do ensino e da aprendizagem, o distintivo principal da função docente (ROLDÃO, 2007), para propiciar o reconhecimento e a assunção de saberes da ação pedagógica (GAUTHIER, 1998).

Sobre os professores formadores, André et al. (2010) oferecem importante contribuição para o debate, tanto pela qualidade do estudo realizado quanto porque a pesquisa sobre esses agentes ainda é bastante exígua entre nós. Em investigação sobre o trabalho do professor formador que atua em cursos de licenciatura, focalizam vários aspectos e desafios constitutivos do seu trabalho, evidenciando entre outros que o contexto de mudança que envolve a escola contemporânea age como elemento transformador do ofício 
docente, visto que o modelo tradicionalmente valorizado de ensino parece não corresponder às novas demandas educativas. Aliado a esse aspecto, sobressai o perfil atual dos licenciandos, que não dispõem de conhecimentos escolares básicos e habilidades essenciais para enfrentar o percurso da formação inicial. Os formadores investigados ressaltam o esforço empreendido para repensar seus saberes e práticas em face dessas novas condições, esbarrando, entretanto, nos obstáculos provocados pelas propostas de formação, pela política institucional e pela cultura docente.

A pesquisa coordenada por André (2010) converge com aspectos apontados por Zeichner (2009), em estudo que focaliza uma agenda de pesquisa para a formação docente. $O$ foco principal da agenda de Zeichner é contribuir para a superação de limitações que cercam esse campo investigativo, ancorando-se na necessária relação entre a pesquisa educacional, a prática e a política de formação de professores. Entre as demandas de pesquisas sugeridas, situa-se a necessidade de investir em estudos que investiguem as consequências de um curso, de seus alunos e de seus professores diante das escolhas de formação, para aumentar o conhecimento sobre o que se faz a favor do aprendizado da docência.

Nessa perspectiva, nossa pesquisa buscou contribuir para o debate sobre a formação de professores, pela via da sua formação em Didática, adotando como principais agentes da investigação os formadores, corroborando, assim, com a direção empreendida por André et al. (2010) e considerando um dos tópicos apontados por Zeichner (2009), carentes de mais investigação, qual seja a necessidade de estudos que relacionem as características do professor, a formação e o aprendizado da docência.

\section{OS PROFESSORES FORMADORES INVESTIGADOS}

Assume-se, no âmbito deste trabalho, a noção de professor formador como aquele que trabalha com processos formativos de professores. $\mathrm{Na}$ pesquisa, como já dito, priorizamos os formadores em Didática.

Do total de 40 participantes da pesquisa, 18 são da universidade pública federal, 9, da pública estadual e 13, da universidade privada. Trinta são mulheres e dez são homens. Boa parte provém de escola pública e de formação superior em universidades federais e estaduais. Muitos têm experiência como professores da educação básica. $\mathrm{Na}$ universidade federal predominam professores que estão iniciando 
carreira na instituição, na condição de efetivos; na universidade estadual prevalecem os professores temporários, na condição de substitutos; e na universidade privada predominam os professores horistas.

O quadro a seguir expõe uma visão panorâmica do perfil dos formadores investigados:

\begin{tabular}{|c|c|c|c|c|}
\hline \multicolumn{2}{|c|}{ Participantes } & Universidade & Universidade & Universidade \\
\hline & & Federal & Estadual & \\
\hline \multirow{2}{*}{ Sexo } & Feminino & 13 & 07 & 09 \\
\hline & Masculino & 05 & 02 & 04 \\
\hline \multirow{3}{*}{ Formação } & Especializacão & 00 & 00 & 04 \\
\hline & Mestrado & 03 & 06 & 06 \\
\hline & Doutorado & 15 & 03 & 03 \\
\hline \multirow{2}{*}{ Cursou Pedagogia } & Sim & 06 & 06 & 08 \\
\hline & Não & 12 & 03 & 05 \\
\hline \multirow{2}{*}{$\begin{array}{l}\text { Exerceu docência } \\
\text { na Edu Básica }\end{array}$} & Sim & 14 & 08 & 11 \\
\hline & Não & 04 & 01 & 02 \\
\hline \multirow{2}{*}{$\begin{array}{l}\text { Experiência } \\
\text { como formador }\end{array}$} & Sim & 09 & 04 & 06 \\
\hline & Não & 09 & 05 & 07 \\
\hline \multicolumn{2}{|c|}{$\begin{array}{c}\text { Condição de trabalho docente na } \\
\text { Universidade }\end{array}$} & 18 Efetivos & $\begin{array}{l}03 \text { Efetivos } \\
06 \text { Substitutos }\end{array}$ & 13 horistas \\
\hline
\end{tabular}

Tabela 2: Perfil dos professores formadores investigados.

Como pode ser observado na tabela 2 , o universo feminino ainda prevalece na profissão docente, mesmo no ensino superior, onde o percentual de representantes do sexo masculino é maior do que na educação básica. A formação dos professores é bem-qualificada, o que se explica em face do processo seletivo para docência nesse nível de ensino, sobretudo em universidades públicas. Esse número mostra-se maior justamente na federal, que, em decorrência da expansão universitária, tem aberto muitos editais para seleção de seu corpo docente. Processo esse que se inicia na Estadual, que, durante o período de realização da pesquisa, contou predominantemente com professores substitutos na disciplina Didática. $\mathrm{Na}$ universidade privada, apesar de ainda contar com a atuação de quatro especialistas, alguns deles já estavam inseridos em programas de mestrado em educação, e alguns dos mestres, por sua vez, já estavam inseridos ou se inserindo em programas de doutoramento, o que revela a busca pela titulação desejável para o exercício docente no ambiente universitário. 
A Didática é um domínio de conhecimento diretamente ligado ao da Pedagogia. Se esta se explica, entre nós, pela teoria e prática da educação, a Didática se explica pela teoria e prática do processo de ensino e de aprendizagem. É esperado, portanto, que os formadores em Didática sejam pedagogos, ou não? Apenas metade dos investigados cursou Pedagogia. Há que se ressaltar que boa parte deles atua com especificidades disciplinares (Didática da Arte, das Ciências Físicas e Biológicas, das Ciências Sociais, da Educação Física, da Filosofia, da Física, da Geografia, da História, da Língua Estrangeira, da Língua Portuguesa, da Matemática, da Química). Estes, com raras exceções, não cursaram Pedagogia. Para trabalharem com Didática na formação de futuros professores, eles recorrem diretamente ao conhecimento da matéria a ser ensinada e à experiência acumulada como professor da educação básica.

Todavia, temos um grupo que trabalha com Didática no seu sentido geral, dialogando diretamente com os fundamentos da prática pedagógica. Alguns, porque atuam com a didática específica, se sentem em condições de atuar também com a geral. Mas encontramos casos em que o professor de Didática não fez Pedagogia e também não atuava com Didática específica. Qual a fonte de conhecimento que lhe serve de base para a formação de futuros professores em Didática? Não somos adeptas da ideia de que professor formador de professor tem que ter cursado Pedagogia. Entretanto, entendemos e defendemos que a condição de formador impõe uma exigência ainda maior ao professor universitário, visto que, como já dito, a prática do formador deve ser parâmetro de constituição da própria prática profissional do professor, tal como defende Gauthier (1998). A questão que se coloca é "Qual é a exigência de formação e de experiência para que o professor ensine Didática"?

O acompanhamento de discussões e proposições referentes ao lugar da Didática nos currículos de formação de professores (GATTI, 2010; LIBÂNEO, 2011, 2008) revela que essa disciplina vem enfrentando um processo de desagregação que inclui a sua substituição por metodologias específicas, alterações na nomenclatura, diminuição de carga horária, deslocamento de seus temários para outras disciplinas, e supressão de abordagens estritamente operacionais. Ora, se, diante disso, o professor que ensina os conhecimentos referentes ao campo da Didática não se constituir como um especialista de estudo da área, pouco poderá contribuir para tornar potente o papel da Didática para a formação e atuação docente. Para Zeichner (2009), “é necessário [haver] mais pesquisas 
que investiguem as consequências de quem está lecionando um determinado componente do curso [...]" (p. 25). De modo mais específico, ao focalizar a necessidade de estudos que relacionem as características do professor, a formação docente, a aprendizagem docente e a prática dos professores, aponta diretamente para o aspecto em questão. $\mathrm{O}$ autor defende que "precisamos saber como as características dos professores e os cursos de formação docente e seus componentes interagem com a aprendizagem docente para mediar esses efeitos nos alunos" (ZEICHNER, 2009, p. 19). Logo, indagamos: quais são as implicações de se organizar a disciplina de Didática como cursos de conteúdos específicos ou como cursos gerais? Quais são as maneiras mais proveitosas de se organizar o ensino de Didática para que as pessoas tenham êxito em diferentes percursos do magistério?

Os dados, tal como dispostos no quadro em questão, registram que a maioria dos investigados reúne experiência como professor da Educação Básica. Na universidade privada e também na estadual, alguns professores trabalhavam concomitantemente nos dois níveis da educação, considerando esse diálogo bastante propício para a formação deles e de seus alunos, futuros professores, tal como se pode verificar na fala de um deles:

Eu digo pra vocês que é muito legal porque de manhã eu sou supervisora de uma escola, eu tenho a prática, e de noite eu lido com a formação teórica na graduação. Não que eu não tivesse a prática à noite, mas a gente acaba colocando em prática o que a gente estuda, mas eu trago muito para os alunos a minha experiência e o que eu vivencio no período da manhã. (Fonte: Entrevista)

Quase a metade dos professores formadores investigados ao assumirem a docência universitária nas instituições participantes da pesquisa reunia alguma experiência de formador em outras instituições. Os iniciantes como professores de Didática declararam a preocupação sentida com a forma de compor e encaminhar a disciplina. Sabemos que o início de um ciclo profissional é sempre tenso, desafiador e hesitoso, porém também sabemos que a lógica academicista tem contribuído para que o papel do formador fique subsumido no de investigador. Isso pode acontecer, sobretudo, porque a força da pesquisa na academia tende a cooptar o docente de uma forma tal que a atividade de ensino é secundarizada e, no caso de cursos de formação de professores, a dimensão de formador do professor é atenuada ao ponto de o professor não se reconhecer como detentor dessa função. Dentre os investigados, nota-se que se manifesta em alguns a mobilização a favor de pensar 
e praticar o ensino considerando a sua dimensão de formador de professores, evidenciando que a escassez de experiência na educação básica e o distanciamento dos estudos sobre Didática podem ser minimizados pelo enfrentamento das questões da prática pedagógica escolar, trazendo-as para o centro do debate e das proposições na sala de aula com os licenciandos, futuros professores.

Nem todos que dão aula de Didática escolheram a disciplina por afinidade, porém por adequação ao concurso público ou em atendimento às exigências da instituição, ou mesmo para aprender sobre os conhecimentos da área, tal como se depreende dos depoimentos abaixo:

Eu ainda tenho uma complementação que é na disciplina Ciências da Educação II, que eu ministro sexta-feira. Mas essa é um apêndice na minha carga horária, porque a minha disciplina é o estágio. (Fonte: Entrevista)

Sou professora de Didática, primeiro porque surgiu a oportunidade de ser professora de ensino superior (...). Segundo, porque eu apostei que iria aprender muito com a Didática e é o que está acontecendo. Eu ia aprender não só teoricamente, me aprofundando ainda mais com os textos, mas também preparando as aulas porque eu tenho que saber do que é que eu vou estar falando...” (Fonte: Entrevista)

As motivações para atuar como formadores de professores no âmbito da Didática se manifestaram em decorrência da experiência de trabalho na escola básica, da continuidade dos estudos no mestrado e no doutorado, da possibilidade de enfrentar um concurso de acesso à carreira docente na universidade pública $\mathrm{e}$ da falta de visibilidade de outra disciplina com mais aderência para atuação, tal como se verifica no excerto a seguir:

Eu sou pedagoga pela Uerj e psicóloga pela PUC. Fiz também psicopedagogia na Uerj e mestrado na área de educação especial também na Uerj. Fiz alguns cursos na área de tecnologia. Sou professora de ensino a distância há mais de dez anos. Comecei minha vida profissional no município do Rio de Janeiro, onde atuei como professora durante quinze anos. Pedi exoneração e entrei no ensino superior. (Fonte: Entrevista)

Um aspecto em especial ganha relevância na análise da maioria das entrevistas. A Didática não foi escolhida porque se constitui um campo investigativo desses professores, mas por conta da experiência como professor e dos conhecimentos disciplinar e pedagógico reunidos (GAUTHIER, 2006).

Dessa forma, o perfil deixa ver a necessidade de investigar mais apuradamente as implicações, na formação de professores, da atuação de formadores que não assumem a Didática como objeto de suas 
investigações, que não reúnem experiência como professores da educação básica e que se encontram no ciclo inicial de sua carreira acadêmica.

\section{O QUE CONTA COMO DIDÁTICA?'}

\subsection{CONCEPC̣ÕES SOBRE DIDÁTICA E SEU REFLEXO NA PROPOSTA DE ENSINO DA DISCIPLINA}

Interrogados sobre como percebem, compreendem e explicam a Didática, os professores mostram uma forte hesitação. Para alguns, não se trata de não saber, porém de reconhecer que o tema é difuso. Historicamente a Didática esteve comprometida com a ideia de técnicas e métodos de ensino. Dizer o que ela é pode fazer emergir um conceito que trai a concepção de docência defendida pelo formador. $\mathrm{O}$ excerto a seguir deixa ver essa hesitação:

Eu não tenho um conceito específico, mas eu acho que a Didática tem que ajudar a pensar no trabalho do professor, nos saberes, no aluno, na escola, no mundo... A Didática é estar no mundo porque não é só a escola. Ela não pode só ficar vinculada, presa, atrelada a um contexto apenas. Ela está ligada a um contexto maior, que passa por uma visão de mundo. Eu não penso na Didática apenas como método, ela tem dimensões... Ela é uma disciplina que tem planos. Então, existe um plano político, um plano filosófico, um plano sociológico... Então, pra falar a verdade, eu não conseguiria conceituar a Didática com clareza e dizer que a Didática é uma disciplina apenas, já que ela envolve muitas relações e comprometimentos políticos. (Fonte: Entrevista)

Para outros, evidencia-se o desconhecimento desse domínio de saber, visto que o campo didático não constitui seu objeto de estudo. A condição de formador na área decorre da responsabilidade de formar professores para uma área específica, como, por exemplo, a Biologia, a Dança, a Educação Física, a Filosofia... Diante da necessidade de compor carga horária e/ou atender a demandas de aumento de oferta de turmas, esses professores incorporam ao seu trabalho a atividade de também dar aulas de Didática.

Eu estou em pânico porque eu não conheço esse campo. Eu vou estudar muito para ensinar Didática. (Fonte: Grupo de Discussão)

Entre reticências, hesitações, desconhecimento e até imprecisão conceitual, notam-se nas falas dos professores formadores as influências de uma visão sobre Didática de cunho mais técnico e instrumental, tal como se pode depreender das falas a seguir:

O que é Didática para mim? Eu entendo Didática como um modo de organização. 
Um processo de pensar o que eu vou fazer e como vou proceder durante a aula. (Fonte: Entrevista)

Didática é metodologia. É a forma que eu ensino. Eu procuro ensinar sempre de uma maneira mais lúdica. (Fonte: Entrevista)

Eu acho assim, que a Didática são esses procedimentos que a gente como professor adota em aula. (Fonte: Entrevista)

Eu conceituo Didática não como uma prática, mas como um método. (Fonte: Entrevista)

Poucos foram os depoentes que expuseram sua concepção sem reticências e, mais que isso, sem resvalar para a tendência tecnicista e indo ao encontro do que propõe a Didática fundamental. $\mathrm{O}$ excerto a seguir é um exemplo da minoria que explicitou clara e seguramente sua concepção:

A Didática é um campo teórico investigativo. É um campo da prática, do ensino, que tem por objeto, no meu entender, o processo de ensino e aprendizagem e todos os agentes que estão nele envolvidos. Isso inclui a prática pedagógica, a sala de aula, o trabalho docente, a relação entre os docentes e os alunos, enfim, incorpora tudo isso aí. O objeto é o processo de ensino aprendizagem, mas o processo de ensino aprendizagem articulado com todos esses agentes que atuam na escola e onde está situada a escola, a rua, o movimento social. (Fonte: Entrevista)

Entendemos que a imprecisão no tocante ao conhecimento didático pode afetar o seu ensino e, consequentemente, a formação em Didática de futuros professores. Evocando mais uma vez a provocação de Zeichner (2009), perguntamos: como as características dos investigados e a forma como conceituam e se relacionam com a Didática interferem na formação e no aprendizado da docência?

$\mathrm{Na}$ universidade privada, a Didática não se constitui como uma disciplina, mas como unidade temática que integra o ementário da disciplina Ciências da Educação II. Nas universidades públicas pesquisadas, a Didática tem o status de disciplina, dividindo-se, em geral e específicas, ainda que a forma de designação não seja essa. A convergência de dados referentes às entrevistas realizadas nas três universidades evidencia que a tendência de trabalhar vários temas ligados à identidade profissional do professor é bastante recorrente. Prevalece uma abordagem permeada de articulações com os conhecimentos das disciplinas de fundamentos da educação para, então, chegar ao núcleo estruturante da Didática, o processo de ensinar e aprender. Nessa perspectiva predomina, entre os investigados, a tendência de ensinar aspectos teóricos que fundamentam as práticas; a relação educação e sociedade; o estabelecimento escolar e 
o trabalho docente; as abordagens de ensino; as teorias de currículo; questões sobre identidade, profissionalidade e saberes docentes; e os componentes da prática pedagógica com atenção especial para planejamento pedagógico e avaliação do ensino e da aprendizagem.

Nota-se que a constituição do campo da Didática no Brasil não é um conhecimento de domínio de boa parte dos entrevistados, sobretudo daqueles que atuam com a Didática específica. Manifestase o receio em relação ao ensino da Didática prescritiva, com predomínio de técnicas, porém a problematização de Candau (1983), acerca da Didática instrumental e da Didática fundamental, parece não fazer parte do idioma pedagógico dos entrevistados. No entanto, aqueles (poucos) que se reportaram à temática, o fizeram com muita propriedade, como se pode depreender do excerto a seguir:

Quando eu falo da constituição do campo da Didática, o objetivo é trazer uma discussão do que pode ser a Didática. Não do que é, porque ninguém é dono dessa definição, mas do que pode ser a Didática e que pode ganhar o nome de Didática. Existem universidades que aboliram essa disciplina, por conta de algumas associações que historicamente aconteceram entre essas disciplinas e algumas atividades pedagógicas, não sei se eu concordo com isso, o fato é que sob esse nome ou outro nome é muito interessante revisitar a história e a reflexão sobre os processos de ensino aprendizagem no Brasil. Alguma confusão na disciplina? Não. Eu sei que isso não é história da educação, mas quando a gente visita, por exemplo, eu parto em geral do seminário a Didática em questão. Aquele momento de ruptura é muito interessante, pra trabalhar com alunos de licenciatura, mas também os de pedagogia, esse momento histórico pra entender o que pode ser a Didática dentro das diversas abordagens. (Fonte: Entrevista)

\subsection{A MEDIAC̣ÃO DO ENSINO NAS AULAS DE DIDÁTICA}

Operando com a visão dos investigados sobre sua própria prática, adotando como objeto de análise suas falas, expressas individualmente nas entrevistas e/ou coletivamente nos grupos de discussão e, considerando as aulas observadas, é possível identificar três tipos de posturas dos formadores.

A primeira postura refere-se à dificuldade de ensinar a ensinar quando a referência se circunscreve ao conhecimento teórico dos temários didáticos. Essa postura manifestou-se especialmente entre os professores que estudam Didática para ensinar, porém não adotam a escola como objeto de suas investigações. A experiência referente ao trabalho na escola é a de aluno. O trabalho de professor, se ocorreu, foi em tempo muito exíguo, não permitindo a consolidação de um 
conhecimento de base sobre formação e trabalho docente. A fala a seguir é representativa dessa posição:

Eu falo nas aulas dessas coisas da escola pública que eu conheço minimamente e os alunos ficam me olhando... porque eles não conhecem e eles não tão lá dentro. Eu também não! É difícil ensinar Didática fora da escola. (Fonte: Grupo de Discussão)

A segunda postura diz respeito à necessidade de construir a disciplina coletivamente com os alunos ao longo do curso, prática que pode ou não culminar em um programa representativo do campo didático. É um risco que o formador prefere assumir, visto que considera mais construtivo definir o percurso do curso com os alunos do que trabalhar com um planejamento prévio. Mesmo que os temários fundamentais da Didática não sejam contemplados, a postura que envolve negociação, dialogicidade e consideração do contexto da turma é, em si mesma, didática. Depreende-se essa posição de uma parcela pequena dos investigados.

Eu sento para pensar os 15 encontros de Didática... Eu não consigo. Fico pensando sobre o que que eu poderia fazer no primeiro encontro... Não sei! Eu não conheço as pessoas. Eu fico impossibilitada de trabalhar. Eu faço isso muito concretamente, começo assim mesmo: "Oi, bom dia! Você veio aqui se matriculou para a disciplina de Didática por quê? O que você está esperando que eu te ensine? Qual é a sua expectativa nisso?" Na verdade é um diálogo. [...] Normalmente, esse programa que a gente desenha no primeiro dia de aula me alimenta para a criação. É um processo criativo mesmo, é como se os alunos me dessem matéria-prima... Eu começo a ter ideias do que dá para fazer e submeto a eles, e eles vão ajudando a criar, provocando os ajustes necessários. (Fonte: Entrevista)

A terceira postura envolve a perspectiva da meta-aula. Alguns formadores preferem trabalhar os conhecimentos da disciplina a partir de uma aula, cujas situações didáticas sejam representativas do tema em estudo. Assim, a ênfase reside na relação forma/conteúdo. Dentre os investigados que afirmam ensinar dessa maneira, tem quem o faça em combinação com os alunos, de forma que eles explicitem a relação teoria/prática reconhecida, e tem quem prefira ensinar dessa forma sem anunciar, deixando os alunos perceberem progressivamente.

Em algumas aulas eu trabalho com meta-aula, ou seja, eu procuro transformar a minha própria aula em ponto de discussão de aula. Então, eu sempre discuto com eles as minhas opções didáticas, minhas opções metodológicas, melhor dizendo procuro diversificar o máximo possível, primeiro porque é um princípio que eu opero de modo geral. Mas, especificamente nas aulas de Didática para que eles vivenciando algumas estratégias de sala de aula possam ir acumulando algum repertório inicial. (Fonte: Entrevista) 
As análises sobre a mediação do ensino nas aulas de Didática têm apontado que os professores buscam ensinar Didática de uma forma ativa, envolvendo trabalho do professor, do aluno, do aluno com aluno e do professor com os alunos, prevalecendo, no entanto, a perspectiva do conhecimento para a prática, conforme discutem Cochran-Smith \& Lytle (1999). Nossos investigados dão prioridade aos trabalhos coletivos, ao diálogo e às trocas de experiências. No caso da universidade privada, grande parte dos professores é horista. Com isso, acumulam outras funções em instituições diversas, sobretudo na educação básica, cujas experiências são socializadas nas aulas que dão para os licenciandos. Muitos graduandos, por sua vez, também já estão atuando nas salas de aula da educação básica, através de estágios remunerados ou como auxiliares de docentes, mesmo sem a certificação. Essa condição, em que pesem os complicadores relacionados à precarização, à proletarização e aos obstáculos à profissionalidade docente, acaba favorecendo o andamento das aulas na licenciatura, em face da circularidade de situações da prática pedagógica na escola de educação básica e da discussão suscitada pelas mesmas. Entretanto, esse processo de ensino não é acompanhado da necessária reflexão sobre a ação na sala de aula e a criação de conhecimento em ação para dar conta de novas situações de aprendizagem (COCHRAN-SMITH \& LYTLE, 1999).

Os professores investigados rechaçam a concepção técnico-instrumental centrada no como ensinar dissociado de sua intencionalidade pedagógica. Eles privilegiam uma prática didática baseada no diálogo com seus alunos. Segundo declararam, os temas trabalhados são discutidos com os futuros professores com forte ênfase na reflexão e na crítica, fazendo com que o ensino de e sobre a Didática se paute pela leitura de textos, debates, levantamento de questões e construções de sínteses. Ainda que alguns formadores ensinem por meio de meta-aula, prevalece, entre os investigados, a perspectiva de que a prática docente é teorizada sem necessariamente considerar a relação forma/conteúdo de suas aulas como objeto de problematização com seus alunos, futuros professores.

A prática ainda representa o nó górdio do aprendizado da docência, apontada, pelos formadores, como o lado mais fraco da formação em Didática. Os investigados declararam o paradoxal sentimento do estudante em relação à parte prática da disciplina. Muitos licenciandos iniciam o curso supondo que o trabalho se voltará para como dar aula. Se de um lado essa expectativa é boa, de outro ela está impregnada de representações prescritivas sobre a 
Didática. O interesse pelo instrumental manifesta-se de forma muito mais forte do que em relação ao fundamental da Didática. Porém, os estudantes supõem que será "muito chato" aprender técnicas de ensino. Assim, a relação inicial dos alunos com a Didática não é boa. Querem aprender como ensinar, porém imaginam que ensinar envolve o domínio de técnicas, conhecimento esse que não desejam acessar. O paradoxo aumenta quando os estudantes se surpreendem com os temas abordados na disciplina, reconhecendo a contribuição da Didática para a sua formação docente, entretanto questionando a ausência de indicativos para a prática pedagógica.

A análise dos dados nos permite afirmar que ensinar Didática não tem sido tarefa fácil para os formadores, visto que o domínio de conhecimento dessa disciplina é, em essência, teórico-prático e a prática, em geral, fica subsumida nas teorizações realizadas, ainda que estas sejam fundamentais para o aprendizado da docência. Para os professores investigados, predomina a variante de que a aula é o espaço/tempo de enfrentamento da relação forma/conteúdo. Como lidar com a problemática que cerca a relação forma/conteúdo no ensino da Didática de modo a não desconsiderar a própria Didática? Como defende Roldão (2007), a função de ensinar é socioprática, mas o saber que requer é teorizador, compósito e interpretativo. A ação de ensinar é inteligente e fundada em um domínio seguro de saber, que emerge de vários saberes formais e do saber experiencial. Dessa forma, o professor precisa saber mobilizar todo o tipo de saber que possui, transformando-o em ato de ensinar enquanto construção de um processo de aprendizagem de outros e por outros. É um caminho possível para assegurar a relação forma/conteúdo em um contexto situado politicamente, contribuindo para a afirmação da Didática fundamental. No dizer da autora, "arte e técnica, mas fundada em ciência” (ROLDÃO, 2007, p. 101).

\section{CONCLUSÃO}

Tentando responder o que é que conta como Didática nos cursos de formação de professores, nossa pesquisa aponta que não há prevalência da Didática instrumental na formação docente oferecida pelas instituições participantes do estudo. Revela-se a tendência de tratamento de uma série de temas necessários à formação de professores, sem, no entanto, se manifestar a preocupação com a afirmação da Didática fundamental, marcada 
pela multidimensionalidade do processo de ensinar e aprender. Há diversificação, o que é, no nosso entender, muito benéfico para a área, mas também há dispersão e, sobretudo, perda do foco, visto que o processo de ensinar e aprender tende a ser secundarizado nas concepções e práticas dos formadores investigados.

A mediação do ensino nas aulas de Didática dos professores participantes da pesquisa parece não se deixar delimitar por tendências específicas. É possível depreender das falas dos investigados que, apesar de cada um adotar um modo peculiar de ensinar, sustentado por uma determinada concepção de ensino, este envolve estratégias que ora se relacionam com a tendência de professar um saber, bastante marcada pela transmissão, assimilação e reprodução de conhecimentos; ora tende ao favorecimento da investigação, da elaboração coletiva, da socialização de saberes e fazeres, mais articulada com a perspectiva de fazer aprender alguma coisa a alguém (ROLDÃO, 2007).

Os resultados apontam que os formadores acreditam que realizam uma prática baseada no diálogo, com estratégias de ensino variadas de acordo com o conteúdo trabalhado. Todavia, ainda não se manifesta a preocupação com a especificidade do saber pedagógico, visto que não é predominante a problematização desses saberes a partir da forma como a própria aula acontece.

Não somos adeptos da Didática instrumental, mas somos a favor de um ensino de Didática que, efetivamente, ajude o futuro professor a compreender a complexidade da mediação didática, com condições de articular saberes dos conteúdos específicos com os dos conteúdos pedagógicos e das suas experiências, à luz das teorias de ensino e de aprendizagem.

Nesse sentido, temos trabalhado para contribuir com o processo de afirmação de uma Didática fundamental, que, em essência, articula o humano, o político e o técnico, a partir de um ensino que se desenvolve em estreita conexão entre conteúdo, mediação e relação pedagógica. Isto é, professor (formador) e aluno (futuro professor) trabalhando em torno do conhecimento sobre a Didática em um contexto situado, problematizando o que, por que, para quem, como e quando ensinar. A relação teoria e prática, própria da Didática, não deve se constituir exclusivamente em um objeto de discussão, mas preferencialmente em vivências na sala de aula e fora dela. O conhecimento sobre o que é a Didática, sobre o que ocorre durante um processo de ensino e de aprendizagem, sobre o conhecimento escolar e suas múltiplas formas de trabalho na perspectiva da inclusão precisa ganhar cada vez mais assento no ensino dessa disciplina. 
Assumimos e defendemos a perspectiva de que o objeto da Didática diz respeito ao processo de compreensão, problematização eproposição acerca do ensino, sendo este entendido como o processo de fazer aprender alguma coisa a alguém, marcado pela mediação e pela dupla transitividade, conforme defende Roldão (2007). Dessa forma, o processo de ensinar incorpora em si mesmo o processo de aprender, constituindo-se como um único processo com movimentos distintos (ensinagem e aprendizagem), porém indissociáveis. Trata-se de favorecer ao professor em formação e em atuação condições de propor formas de mediação da prática pedagógica, fundamentadas por concepções que permitam situar a função social de tais mediações. Não se trata, pois, de enfatizar

o como fazer, porém o como fazer (mediação) em articulação ao por que fazer (intencionalidade pedagógica), condição intrínseca da Didática fundamental.

Considerando o que defende Roldão (2007), o professor profissional é aquele que ensina não apenas porque sabe, mas porque sabe ensinar. Saber ensinar é ser especialista da complexa capacidade de transformar o saber curricular mediado por um saber científico, por um domínio técnico-didático rigoroso, por uma postura meta-analítica, de questionamento intelectual da ação, de interpretação permanente e realimentação contínua, para que o aluno aprenda de forma contextualizada e com significado.

\section{REFERÊNCIAS}

ANDRÉ, Marli et al. O trabalho docente do professor formador no contexto atual das reformas e das mudanças no mundo contemporâneo. Revista Brasileira de Estudos Pedagógicos, Brasília, v. 91, n. 227, p. 122-143, jan./abr. 2010.

ANDRÉ, Marli. Tendências da pesquisa e do conhecimento didático no início dos anos 2000. In: Encontro Nacional de Didática e Prática de Ensino. Trajetórias e processos de ensinar e aprender: Didática e formação de professores. XV ENDIPE. Rio Grande do Sul: EDIPUCRS, 2008. [487-499]

CANDAU, Vera. (org.). Didática: questões contemporâneas. Rio de Janeiro: Vozes, 2009.

. A Didática hoje: uma agenda de trabalho. In: CANDAU, Vera. Didática, currículo e saberes escolares. Rio de Janeiro: DP\&A, 2000. [149-160]

Rumo a uma nova didática. Rio de Janeiro: Vozes, 1988.

A Didática em questão. Rio de Janeiro: Vozes, 1983.

COCHRAN-SMITH, Marilyn; LYTLE, Susan Landy. Relationships of Knowledge and Practice: teacher learning in communities. In: Review of Research in Education. USA, 24, p. 249-305, 1999. 
GATTI, Bernardete. Formação de professores no Brasil: características e problemas. Educação \& Sociedade, Campinas, v. 31, n. 113, p. 1355-1379, out.-dez. 2010.

GAUTHIER, Clermont et al. Por uma teoria da pedagogia: pesquisas contemporâneas sobre o saber docente. Ijuí: Ed. Unijuí, 1998.

LIBÂNEO, José Carlos. O campo teórico e profissional da Didática hoje: entre Ítaca e o canto das sereias. In: Encontro Nacional de Didática e Prática de Ensino. Trajetórias e processos de ensinar e aprender: Didática e formação de professores. XV ENDIPE. Rio Grande do Sul: EDIPUCRS, 2008. [234-251]

Panorama do ensino da Didática, das metodologias específicas e das disciplinas conexas nos cursos de Pedagogia: repercussões na qualidade da formação profissional. In: LONGAREZI, A. M.; PUENTES, R. V. (orgs.). Panorama da Didática: ensino, prática e pesquisa. São Paulo: Papirus, 2011. [11-50]

LÜDKE, Menga (coord.). O que conta como pesquisa? São Paulo: Cortez, 2009.

MARTINS, Pura Lúcia Oliver. O campo da didática: expressão das contradições da prática. In: Encontro Nacional de Didática e Prática de Ensino. Trajetórias e processos de ensinar e aprender: Didática e formação de professores. XV ENDIPE. Rio Grande do Sul: EDIPUCRS, 2008. [585-601]

OLIVEIRA, Maria Rita Neto Sales. 20 anos de ENDIPE. In: CANDAU, Vera. (org.). Didática, currículo e saberes escolares. Rio de Janeiro: DP\&A, 2000. [161-106-176] . Confluências e divergências entre didática e currículo. Campinas: Papirus, 1998.

. A pesquisa em Didática no Brasil. In: PIMENTA, S. G. (org.). Didática e formação de professores: percursos e perspectivas no Brasil e em Portugal. São Paulo: Cortez, 1997. [131-157]

- A reconstrução da didática: elementos teórico-metodológicos. Campinas: Papirus, 1992.

PIMENTA, Selma Garrido. A pesquisa em Didática - 1996-1999. In: CANDAU, Vera. (org.). Didática, currículo e saberes escolares. Rio de Janeiro: DP\&A, 2000. [78-106]

Para uma re-significação da Didática: ciências da educação, pedagogia e didática. (Uma revisão conceitual e uma síntese provisória) In: PIMENTA, S. G. (org.). Didática e formação de professores - percursos e perspectivas no Brasil e em Portugal. São Paulo: Cortez, 1997.

ROLDÃO, Maria do Céu. Função docente: natureza e construção do conhecimento profissional. Revista Brasileira de Educação. Rio de Janeiro, v. 12, n. 34, p. 94-181, jan./abr. 2007.

SHULMAN, Lee. Conocimiento y enseñanza: fundamentos de la nueva reforma. Professorado. Revista de currículum y formación del professorado, 9, 2 (2005) España (p. 1-30).

TARDIF, Maurice. Saberes docentes e formação profissional. Petrópolis: Vozes, 2002.

VEIGA, Ilma Passos de Alencastro. A prática pedagógica do professor de didática. Campinas: Papirus, 1989.

WELLER, Wivian. Grupos de discussão: aportes teóricos e metodológicos. In: WELLER, Wivian.; PFAFF, Nicolle. (orgs.). Metodologias da pesquisa qualitativa em educação: teoria e prática. Petrópolis/RJ: Vozes, 2010. [54-66].

ZEICHNER, Kenneth. Uma agenda de pesquisa para a formação docente. Revista Brasileira de Pesquisa sobre Formacão Docente. Belo Horizonte: Autêntica, v. 1, n. 1, p. 13-40, ago./dez. 2009. 


\section{NOTAS}

${ }^{1}$ Parafraseando título de pesquisa e de livro coordenado pela Professora Menga Lüdke "O que conta como Pesquisa?" (2009).

Recebido: 30/04/2013

Aprovado: 11/09/2014

Contato:

Universidade Federal do Rio de Janeiro Faculdade de Educação Departamento de Didática Av. Pasteur, s/n - Fundos Praia Vermelha/Botafogo Rio de Janeiro | RJ | Brasil

CEP 22.290-240 
